\title{
Effects of lycium barbarum polysaccharides on neuropeptide $Y$ and heat-shock protein 70 expression in rats exposed to heat
}

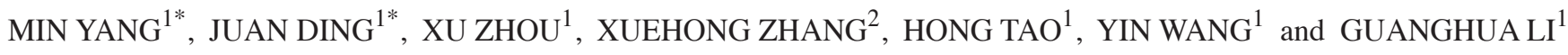 \\ ${ }^{1}$ Department of Physiology, School of Basic Medical Science, Ningxia Medical University; ${ }^{2}$ Department of Pediatrics, \\ General Hospital of Ningxia Medical University, Yinchuan, Ningxia 750004, P.R. China
}

Received March 27, 2014; Accepted May 19, 2014

DOI: $10.3892 /$ br.2014.291

\begin{abstract}
The purpose of the present study was to investigate the effects of high ambient temperature on the neuropeptide $\mathrm{Y}$ (NPY) mRNA level in the hypothalamus, the plasma concentration of corticotropin-releasing hormone (CRH), cortisol (Cor), heat-shock protein 70 (HSP70) and epinephrine (EPI), and the intervention of lycium barbarum polysaccharides (LBPs) in rats. Compared to the control (CN) group, the plasma levels of CRH, Cor, HSP70 and EPI were markedly increased, and the level of NPY mRNA was downregulated in the high ambient temperature (HT) group. By contrast, rats in the HT + LBP (HTL) group had: i) a significantly enhanced expression of HSP70 compared to the HT and CN groups; ii) clearly increased plasma levels of $\mathrm{CRH}$, Cor and EPI compared to the CN group; and iii) a markedly upregulated expression of NPY mRNA compared to the HT group. Thus, the results showed that high-temperature environments may damage the body, and LBPs have a potentially protective function by increasing the expression of HSP70 and NPY.
\end{abstract}

\section{Introduction}

The physical factors of the human environment include temperature, humidity and noise. Living permanently in a high ambient temperature affects the daily life and work environment. More importantly, a high humidity and noisy environment cause damage to the body (1). Among these physical environmental stresses, temperature is the most significant ecological condition. As temperature is a factor that is widespread in the majority of environments, there is a lack of space or time stability (2). High ambient temperature beyond the scope of the thermal neutral zone has been considered

Correspondence to: Dr Guanghua Li, Department of Physiology, School of Basic Medical Science, Ningxia Medical University, 1160 Shengli Street, Xingqing, Yinchuan, Ningxia 750004, P.R. China E-mail: ghlee0404@163.com

${ }^{*}$ Contributed equally

Key words: high-temperature environments, heat-shock protein 70, neuropeptide Y, lycium barbarum polysaccharides to be the deadliest pressure source in rodents, as it triggers a wide variety of biological responses, and results in neurological, endocrine disorders and immune dysfunctions (3). Under the action of stress, a number of hormones are excreted to counteract the adverse effect on organism function. The stress hormones (catecholamines, glucocorticoid and growth hormone) play a critical role in regulating the circulation and nutritional requirement of potentially harmful situations, via the 'flight or fight' reaction (4).

Lycium barbarum belongs to the plant family Solanaceae. The red berries, also known as wolfberry or gou qi zi, are a well-known traditional Chinese medicine. Currently, the red berries have been extensively used to manufacture various types of healthy foods and products, including medicinal beverages and healthy soups (5). Lycium barbarum has a high level of polysaccharides, which is analogously $40 \%$ by dry mass, and therefore, studies have been devoted to the liquid fraction of the berries and the lycium barbarum polysaccharides (LBPs) (6). It has been previously reported that LBPs act against the influences of aging and oxidation $(7,8,9)$, adjust the immune function $(10,11)$, increase the exercise tolerance capacity, relieve fatigue and aging, and express antioxidant activity (12-14). Treatment with LBP prevented the rise of blood glucose in hypertensive rats, guarded against liver damage caused by alcohol-induced oxidative stress in rats (15-17), and reduced the side-effects of chemotherapy and radiotherapy in the treatment of cancer (18-20). Our previous study showed that LBP clearly inhibited oxidative stress, weakened the contractile response to noradrenaline, and it also enhanced the expression of endothelial nitric oxide synthase and heat-shock protein 70 (HSP70) in rats undergoing exhaustive exercise (21).

The objectives of the present study were: i) to investigate the effects of high ambient temperature on neuropeptide $\mathrm{Y}$ (NPY) gene expression in the hypothalamus and the concentration of corticotropin-releasing hormone (CRH), cortisol (Cor), HSP70 and epinephrine (EPI) in the plasma of rats; and ii) to examine the alleviating effects of LBP intervention under high ambient temperatures on these physiological parameters in Sprague-Dawley (SD) rats.

\section{Materials and methods}

Animals and heat exposure schedule. Five-week-old male SD rats, weighing 150-180 g, were purchased from the 
Table I. GenBank login code, primer sequences and forecast size of the amplification products.

\begin{tabular}{llllr}
\hline Gene & GenBank & \multicolumn{1}{c}{ Forward primer } & \multicolumn{1}{c}{ Reverse primer } & bp \\
\hline NPY & NM_012614 & GCTCTGCGACACTACATCAATC & GCATTTTCTGTGCTTTCTCTCA & 107 \\
$\beta$-actin & NM_031144 & CACCCGCGAGTACAACCTTC & CCCATACCCACCATCACACC & 207 \\
\hline
\end{tabular}

bp, base pair; NPY, neuropeptide Y.

Laboratory Animal Center of Ningxia Medical University (Yinchuan, China). The rats were placed individually in plastic cages and were maintained on a 12-h light/dark cycle (lights on between 08:00 and 20:00 h) at a normothermic temperature $\left(24.0 \pm 1^{\circ} \mathrm{C}\right)$, with access to food and water at liberty. The experimental procedures were approved by the Animal Ethics Committee of Ningxia Medical University and in accordance with the guidelines of the Council of the Physiological Society of China (?). Following a week-long adaptive phase, 24 rats were randomly divided into the control $(\mathrm{CN})$, high ambient temperature (HT) and HT + LBP (HTL) groups. The temperature inside the climatic chamber was raised to $32.0 \pm 0.2^{\circ} \mathrm{C}$ (relative humidity, $60 \pm 5 \%$ ) in the HT and HTL groups, whereas the rats in the $\mathrm{CN}$ group were maintained at a temperature of $24.0 \pm 1^{\circ} \mathrm{C}$ throughout the study. In the HTL group, the rats were treated with LBP by gavage [ $200 \mathrm{mg} / \mathrm{kg}$ body weight (b.w.)], whereas the rats in the $\mathrm{HT}$ and $\mathrm{CN}$ groups were treated with normal saline by gavage $(1 \mathrm{ml} / 100 \mathrm{~g}$ b.w.). The treatments lasted for 14 days. The dose of LBP was chosen according to prophase experiments (21) and it was safe, effective and non-toxic in rats. In the course of the experiment, cages were cleaned and food and water were replaced at a random time every 2 or 3 days.

Tissue sampling and organ preparation. Following heat exposure, each rat was anesthetized by intraperitoneal injection of urethane $(1.5 \mathrm{~g} / \mathrm{kg})$. Blood was extracted from the abdominal vein with a syringe, which was washed by heparin sodium solution prior to use. Subsequently, the blood was centrifuged at 3,500 x g for $15 \mathrm{~min}$ to obtain plasma. The plasma was stored at $-80^{\circ} \mathrm{C}$ until analysis.

The rats were executed by cervical dislocation, and the whole brain and hypothalamus were immediately removed and placed into liquid nitrogen. Frozen samples were reserved at $-80^{\circ} \mathrm{C}$ until further analysis.

$R N A$ extraction and quantitative polymerase chain reaction $(q P C R)$. RNA was extracted from hypothalamic tissue ( $\mathrm{n}=8$ in each group for the NPY mRNA assay), using an Axygen RNA kit (Axygen Biosciences, Union City, CA, USA) according to the manufacturer's instructions. Total RNA concentrations were measured by spectrophotometry at $260 \mathrm{~nm}$. The purity of the RNA samples $(260 / 280)$ was: $1.65 \leq$ purity $\leq 2.00$. cDNA was synthesized using a reverse transcription kit (TransGen Biotech Co., Ltd., Beijing, China) according to the manufacturer's instructions. qPCR was carried out using a Top Green qPCR SuperMix (TransGen Biotech Co., Ltd.). Primer sequences and the amplified fragment size are listed in Table I [Sangon Biotech (Shanghai) Co., Ltd., Songjiang, Shanghai,
China]. The specificity of the PCR amplified products was authenticated by analysis of a melting curve and agarose gel electrophoresis. The PCR conditions were as follows: $94^{\circ} \mathrm{C}$ for $5 \mathrm{~min}$ (initial activation) followed by 36 cycles of amplification at $94^{\circ} \mathrm{C}$ for $30 \mathrm{sec}$ for denaturation; $62^{\circ} \mathrm{C}$ for $30 \mathrm{sec}$ for annealing; and $72^{\circ} \mathrm{C}$ for $30 \mathrm{sec}$ for extension. At the end of each reaction, melting curve analyses were performed to ensure the specificity of each reaction. The $2^{-\Delta \Delta \mathrm{Ct}}$ method was used to calculate and correct the values of mRNA. In each run, the control sample was an internal standard, followed by standardization to the $\beta$-actin mRNA level. In the original experiment, the amplification efficiencies of NPY and $\beta$-actin were measured, and all amplification efficiencies were comparable. In each sample, the $\Delta \mathrm{Ct}$ value was established by measuring the difference between the Ct of NPY and $\beta$-actin as follows: $\Delta \mathrm{Ct}=\mathrm{Ct}(\mathrm{NPY})-\mathrm{Ct}(\beta$-actin). Subsequently, the $\Delta \Delta \mathrm{Ct}$ of each sample was calculated by deducting the $\Delta \mathrm{Ct}$ value of the control: $\Delta \Delta \mathrm{Ct}=\Delta \mathrm{Ct}$ (sample) $-\Delta \mathrm{Ct}$ (control). Each sample of RNA was tested three independent times and the average was used for the value in each sample.

Measurements of plasma CRH, Cor, HSP7O and EPI concentrations. The plasma concentrations of CRH, Cor, HSP70 and EPI were detected by an ELISA kit (Cusabio Biotech Co., Ltd., Wuhan, Hubei, China), and all procedures were performed according to the manufacturer's instructions $(n=8$ in each group). Samples were arranged in replicates and the average value of each sample was used for analysis.

Statistics. The values are provided as mean \pm standard deviation. Statistical comparisons were made by one-way analysis of variance. The statistical analyses were performed with SPSS version 16.0 (SPSS, Inc., Chicago, IL, USA). P $<0.05$ was considered to indicate a statistically significant difference.

\section{Results}

Plasma CRH concentrations. In the plasma, the concentration of CRH significantly increased in the HT $(\mathrm{P}<0.05)$ and HTL $(\mathrm{P}<0.05)$ groups compared to the $\mathrm{CN}$ group. The plasma $\mathrm{CRH}$ level in the HTL group was not significant compared with that of the HT group ( $\mathrm{P}>0.05)$ (Fig. 1).

Plasma Cor concentrations. Plasma Cor levels were significantly increased in the HT and HTL rat groups that were exposed to the high ambient temperature $(\mathrm{P}<0.05)$, compared to the rats in the $\mathrm{CN}$ group. However, there were no clear differences in the plasma Cor levels between the HT and HTL groups ( $\mathrm{P}>0.05)$ (Fig. 2). 


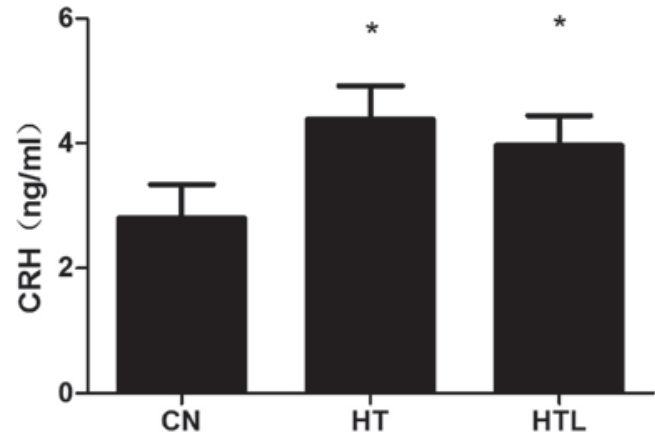

Figure 1. Effects of high ambient temperature and LBP intervention on the level of CRH $(\mathrm{ng} / \mathrm{ml})$ in the plasma of rats. Data are shown as mean \pm standard deviation $(\mathrm{n}=8) .{ }^{*} \mathrm{P}<0.05$ compared with $\mathrm{CN}$. LBP, lycium barbarum polysaccharides; $\mathrm{CRH}$, corticotropin-releasing hormone; $\mathrm{CN}$, control group; HT, high ambient temperature group; HTL, high ambient temperature + LBP group.

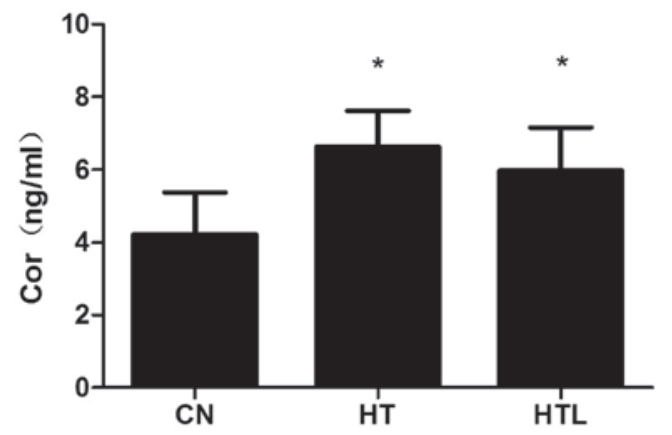

Figure 2. Effects of high ambient temperature and LBP intervention on the level of Cor $(\mathrm{ng} / \mathrm{ml})$ in the plasma of rats. Data are shown as mean \pm standard deviation ( $\mathrm{n}=8)$. " $\mathrm{P}<0.05$ compared with $\mathrm{CN}$. LBP, lycium barbarum polysaccharides; Cor, cortisol; CN, control group; HT, high ambient temperature group; HTL, high ambient temperature + LBP group.

Plasma HSP70 concentrations. After 14 days of heat exposure, the plasma level of HSP70 in the HT group was significantly $(\mathrm{P}<0.05)$ higher compared with the $\mathrm{CN}$ group, whereas the plasma HSP70 level in the HTL group was markedly $(\mathrm{P}<0.05)$ higher compared with the HT group (Fig. 3).

Plasma EPI concentrations. After 14 days of heat exposure, the plasma EPI level in the HT $(\mathrm{P}<0.05)$ or HTL $(\mathrm{P}<0.05)$ group was significantly higher compared with the $\mathrm{CN}$ group. The EPI level in the plasma of the HTL group was not significantly different compared with the HT group ( $\mathrm{P}>0.05)$ (Fig. 4).

NPY mRNA expression. The mRNA expression level of NPY was significantly downregulated in the HT group compared with the $\mathrm{CN}$ group $(\mathrm{P}<0.05)$. The expression of NPY mRNA markedly increased in the HTL group compared with the HT group $(\mathrm{P}<0.05)$. However, there were no significant differences in the levels of NPY mRNA between the CN and HTL groups ( $\mathrm{P}>0.05$ ) (Fig. 5).

\section{Discussion}

In the present study, the primary purpose was to investigate the effects of high ambient temperature on the physiological parameters in SD rats. Our previous study showed that the

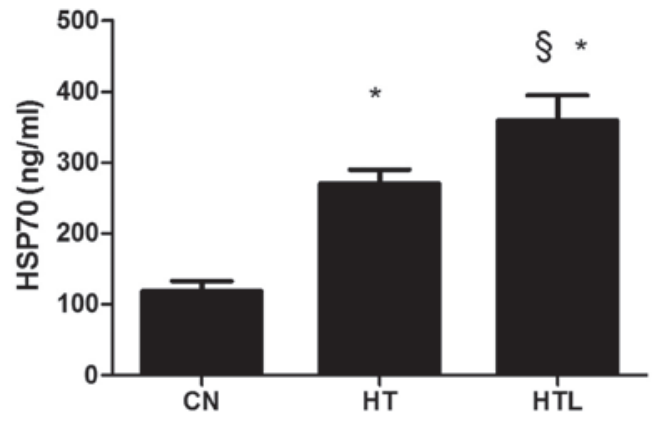

Figure 3. Effects of high ambient temperature and LBP intervention on the level of HSP70 $(\mathrm{ng} / \mathrm{ml})$ in the plasma of rats. Data are shown as mean \pm standard deviation $(\mathrm{n}=8)$. ${ }^{*} \mathrm{P}<0.05$ compared with $\mathrm{CN},{ }^{\circledR} \mathrm{P}<0.05$ compared with HT. LBP, lycium barbarum polysaccharides; HSP70, heat-shock protein 70; $\mathrm{CN}$, control group; HT, high ambient temperature group; HTL, high ambient temperature + LBP group.

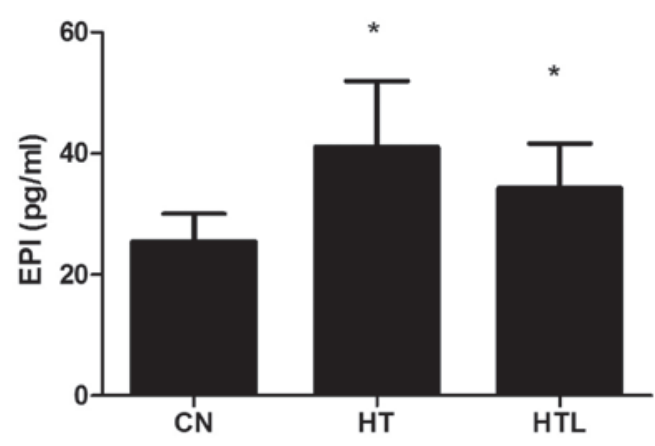

Figure 4. Effects of high ambient temperature and LBP intervention on the level of EPI $(\mathrm{pg} / \mathrm{ml})$ in the plasma of rats. Data are shown as mean \pm standard deviation $(n=8)$. ${ }^{*}<0.05$ compared with $\mathrm{CN}$. LBP, lycium barbarum polysaccharides; EPI, epinephrine; $\mathrm{CN}$, control group; HT, high ambient temperature group; HTL, high ambient temperature + LBP group.

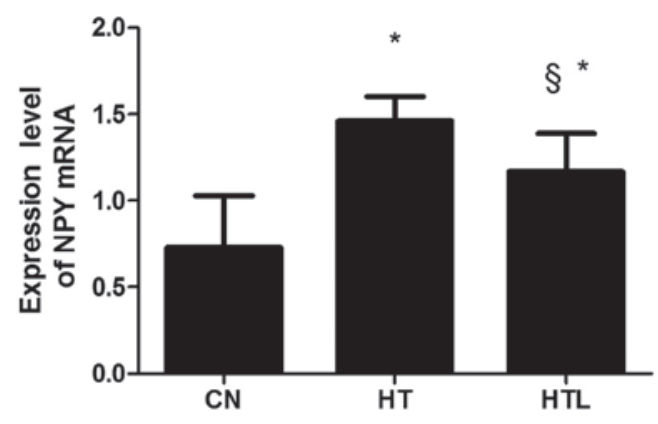

Figure 5. Effects of high ambient temperature and LBP intervention on the expression of NPY mRNA in the hypothalamus of rats. Data are shown as mean \pm standard deviation $(n=8)$. ${ }^{*} \mathrm{P}<0.05$ compared with $\mathrm{CN},{ }^{\S} \mathrm{P}<0.05$ compared with HT. LBP, lycium barbarum polysaccharides; NPY, neuropeptide Y; CN, control group; HT, high ambient temperature group; HTL, high ambient temperature + LBP group.

mean abdominal temperature (Tab) in the light and dark phases of day in the HT and HTL groups was slightly higher than those of the $\mathrm{CN}$ group, but Tab did not differ between these groups (22). High ambient temperature has a negative impact on the performance of the neuroendocrine system. The hypothalamic-pituitary-adrenal (HPA) axis is an important part of the neuroendocrine system and its main action is to connect the functions of the hypothalamus, pituitary 
gland and adrenal cortex (23). The HPA axis, not only regulates and controls the reaction to stress, but also has a number of other functions, including body heat regulation, the regulation of metabolism and immune function. The HPA axis plays a key role in the process of stress response by regulating the secretion of Cor. Cor is widely accepted as a standard for stress response as secretion of Cor has been shown to increase when animals are exposed to a stress state (24). The stress-induced activation of the HPA axis is dependent on $\mathrm{CRH}$, which is the primary regulator of stress. $\mathrm{CRH}$ activates the HPA axis by inducing the release of the adrenocorticotropic hormone (ACTH) from the pituitary gland, which in turn stimulates the adrenocortical release of Cor (25).

In humans, $\mathrm{CRH}$ is the major hormone of the HPA axis. CRH is a 41-amino-acid neuropeptide, which is produced and released by the hypothalamus. When the body is exposed to a stressful environment, $\mathrm{CRH}$ is released by the hypothalamus (26-29). A study by Elias et al (30) showed that the concentration of Cor and CRH was increased immediately, following a long-time high-intensity exercise. Results of the present study have shown that exposure to high ambient temperature increased the level of CRH in plasma. When the secretion of $\mathrm{CRH}$ increases, $\mathrm{CRH}$ stimulates the cells of the anterior pituitary to synthesize and release the ACTH, which in turn stimulates the cells of the adrenal cortex to synthesize and release Cor $(31,32)$. A previous human study has shown that Cor is the end result of the HPA-axis activation (33). Cor can also be considered a reliable indicator of the initial strength of nauseous or harmful events (34). Megahed et al (35) showed that in Upper Egypt, the summer heat stress induced the increase of Cor in the serum of Buffalo-Cows. The present study has confirmed that exposure to high ambient temperature caused a significant increase in the Cor plasma level. Therefore, the study has shown that high ambient temperature exposure causes a clear activation of the HPA axis, manifested as the increased secretion of $\mathrm{CRH}$ and Cor. Based on these data, there was no significant difference between the HTL and HT groups in the rat plasma levels of Cor and CRH. This finding may indicate that LBP had no evident effect on the alleviation of the increased plasma levels that were caused by heat stress.

HSPs are molecular chaperones, that play a crucial role in protein transport, aggregation, degradation, folding and unfolding (36). Furthermore, these highly-conserved proteins belong to the stress-responsive protein family, and play a key role in protecting cells against stress and apoptosis (37). Hsp70 is one of the largest and most conserved families that participate in cytothesis and other protective mechanisms (38). In addition, various types of environmental stresses and toxic chemical substances are able to upregulate the expression of Hsp70 (39-41). It is known that HSP play important physiological actions in situations involving both pantosomatous and cellular stress. HSP reacts quickly to environmental stress, and also protects cells from it. Additionally, all manner of environmental stresses and nocuous chemical materials induce the expression of HSP70. Yu and Bao (42) reported that heat stress induced an increase in HSP70 protein and mRNA levels in the heart and liver of broiler chickens. Thus, in the present study, the plasma level of HSP70 was detected in rats exposed to high ambient temperature. The data show that the levels of HSP70 in the HT and HTL groups were significantly increased compared to the $\mathrm{CN}$ group. The data also show that the level of HSP70 was markedly increased in LBP-treated animals compared to the HT group. In addition, the upregulation of NPY mRNA expression was observed in the LBP-treated rats. Therefore, HSP70 may participate in this upregulation by protecting the cells from the deleterious effects of heat stress.

A large-scale stress-antileptic physiological reaction refers to a complicated neural endocrine, and the interaction between the immune system to preserve internal homeostasis and to respond to life-threatening unexpected events (43). The first sign of the stress response is the activation of the sympathetic nervous system. This activation increases the release of catecholamines and the release of co-located substances, including neuropeptides at the sympathetic neuroeffector juncture into the blood. For a number of years, it has been known that stress induces a cascade of adaptive neuroendocrine responses, which generally includes the synthesis and release of Cor and EPI from the adrenal gland $(44,45)$. Melin et al showed that when rats were exposed to heat stress followed by exhaustive exercise, the levels of EPI and norepinephrine were increased (46). In the present study, it was demonstrated that high temperature exposure increased the plasma level of EPI, and that there was no significant change in the HTL group compared with the HT group. This suggests that LBP had no obvious effect on alleviating the increased plasma EPI level that was caused by heat stress.

NPY is a 36-amino acid peptide, which is widely distributed in the central and peripheral nervous system of mammals. NPY plays a decisive role in maintaining the homeostasis of the internal environment (47). Whether in humans or animals, stressors, including cold, electroshock and exercise, can increase the plasma NPY levels has also been investigated (48). The NPY gene expression was elevated by a acute stress, whereas the NPY gene expression was different in a reduplicated stress (49). NPY is a primary neurotransmitter activated by stress that has been widely studied in the field of anxiety and stress. In the present study, in the rats exposed to high ambient temperature, a significant downregulation in the mRNA expression of NPY was observed. This may indicate that prolonged heat stress may cause injury to the body. The downregulation was entirely reversed by the intervention of LBPs in the HTL group.

The present study has shown that LBP enhanced the expression of HSP70 in plasma. LBP treatment was also shown to reverse the downregulation of NPY mRNA expression. This may indicate that LBP alleviates the harm caused by prolonged heat stress. However, the mechanism of the increased NPY mRNA expression in LBP-treated rats has not examined thoroughly in the study, and further investigation is required to investigate this mechanism.

In conclusion, results of the present study have shown a significant increase in the plasma concentration of $\mathrm{CRH}$, Cor, HSP70 and EPI in rats exposed to high ambient temperature. By contrast, LBP significantly increased the plasma level of HSP70 and the mRNA expression of NPY, to protect the body from the damage caused by heat stress. 


\section{Acknowledgements}

The present study was supported by the National Natural Science Foundation of China (grant no. 81060230) and the Ningxia Natural Science Foundation Key Project (grant no. NZ13055).

\section{References}

1. Yun SH, Moon YS, Sohn SH and Jang IS: Effects of cyclic heat stress or vitamin $C$ supplementation during cyclic heat stress on HSP70, inflammatory cytokines, and the antioxidant defense system in Sprague Dawley rats. Exp Anim 61: 543-553, 2012.

2. Sohail MU, Ijaz A, Yousaf MS, et al: Alleviation of cyclic heat stress in broilers by dietary supplementation of mannan-oligosaccharide and Lactobacillus-based probiotic: dynamics of cortisol, thyroid hormones, cholesterol, C-reactive protein, and humoral immunity. Poult Sci 89: 1934-1938, 2010.

3. Lamb JR, Bal V, Mendez-Samperio P, et al: Stress proteins may provide a link between the immune response to infection and autoimmunity. Int Immunol 1: 191-196,1989.

4. Power ML and Schulkin J: Functions of corticotropin-releasing hormone in anthropoid primates: from brain to placenta. Am J Hum Biol 18: 431-447, 2006.

5. Li SY, Yang D, Yeung CM, et al: Lycium barbarum polysaccharides reduce neuronal damage, blood-retinal barrier disruption and oxidative stress in retinal ischemia/reperfusion injury. PLoS One 6: e16380, 2011.

6. Chang RC and So KF: Use of anti-aging herbal medicine, Lycium barbarum, against aging-associated diseases. What do we know so far? Cell Mol Neurobiol 28: 643-652, 2008.

7. Cheng D and Kong H: The effect of Lycium barbarum polysaccharide on alcohol-induced oxidative stress in rats. Molecules 16 2542-2550, 2011

8. Li XM, Ma YL and Liu XJ: Effect of the Lycium barbarum polysaccharides on age-related oxidative stress in aged mice. J Ethnopharmacol 111: 504-511, 2007.

9. Yu MS, Lai CS, Ho YS, et al: Characterization of the effects of anti-aging medicine Fructus lycii on beta-amyloid peptide neurotoxicity. Int J Mol Med 20: 261-268, 2007.

10. Du G, Liu L and Fang J: Experimental study on the enhancement of murine splenic lymphocyte proliferation by Lycium barbarum glycopeptide. J Huazhong Univ Sci Technolog Med Sci 24 518-520, 527, 2004

11. Gan L, Zhang SH, Liu Q and Xu HB: A polysaccharide-protein complex from Lycium barbarum upregulates cytokine expression in human peripheral blood mononuclear cells. Eur J Pharmacol 471: 217-222, 2003

12. Zhang X: Experimental research on the role of Lycium barbarum polysaccharide in anti-peroxidation. China J Chin Mater Med 18: 110-112, 1993 (In Chinese)

13. Luo Q, Yan J and Zhang S: Isolation and purification of Lycium barbarum polysaccharides and its antifatigue effect. J Hyg Res 29: 115-117, 2000 (In Chinese).

14. Yao LQ and Li FL: Lycium barbarum polysaccharides ameliorates physical fatigue. Afr J Agric Res 5: 2153-2157, 2010.

15. Xiao J, Liong EC and Ching YP: Lycium barbarum polysaccharides protect rat liver from non-alcoholic steatohepatitis-induced injury. Nutr Diabetes 3: e81, 2013.

16. Ha KT, Yoon SJ, Choi DY, Kim DW, Kim JK and Kim CH: Protective effect of Lycium chinense fruit on carbon tetrachloride-induced hepatotoxicity. J Ethnopharmacol 96: 529-535, 2005.

17. Luo Q, Cai Y, Yan J, Sun M and Corke H: Hypoglycemic and hypolipidemic effects and antioxidant activity of fruit extracts from Lycium barbarum. Life Sci 76: 137-149, 2004.

18. Miao Y, Xiao B, Jiang Z, et al: Growth inhibition and cell-cycle arrest of human gastric cancer cells by Lycium barbarum polysaccharide. Med Oncol 27: 785-790, 2010.

19. Gong H, Shen P, Jin L, Xing C and Tang F: Therapeutic effects of Lycium barbarum polysaccharide (LBP) on irradiation or chemotherapy-induced myelosuppressive mice. Cancer Biother Radiopharm 20: 155-162, 2005.

20. Hai-Yang G, Ping S, Li JI, Chang-Hong X and Fu T: Therapeutic effects of Lycium barbarum polysaccharide (LBP) on mitomycin C (MMC)-induced myelosuppressive mice. J Exp Ther Oncol 4: 181-187, 2004.
21. Zhao Z, Luo Y, Li G, Zhu L, Wang Y and Zhang X: Thoracic aorta vasoreactivity in rats under exhaustive exercise: effects of Lycium barbarum polysaccharides supplementation. J Int Soc Sports Nutr 10: 47, 2013.

22. Li G, Li H, Zhang Q, Liu H, Zhou X and Osamu S: Effects of heat exposure on weight of stress organ and intervention of LBP in rats. Liaoning J Trad Chin Med 34: 45-47, 2012.

23. Mahmoud KZ, Edens FW, Eisen EJ and Havenstein GB: Effect of ascorbic acid and acute heat exposure on heat shock protein 70 expression by young white Leghorn chickens. Comp Biochem Physiol C Toxicol Pharmacol 136: 329-335, 2003.

24. Collip D, Nicolson NA, Lardinois M, et al; G.R.O.U.P.: Daily cortisol, stress reactivity and psychotic experiences in individuals at above average genetic risk for psychosis. Psychol Med 41: 2305-2315, 2011

25. Rivier CL and Plotsky PM: Mediation by corticotropin releasing factor (CRF) of adenohypophysial hormone secretion. Annu Rev Physiol 48: 475-494, 1986.

26. Thorsell A: Brain neuropeptide $\mathrm{Y}$ and corticotropin-releasing hormone in mediating stress and anxiety. Exp Biol Med (Maywood) 235: 1163-1167, 2010.

27. Wang SS, Yan XB, Hofman MA, Swaab DF and Zhou JN: Increased expression level of corticotropin-releasing hormone in the amygdala and in the hypothalamus in rats exposed to chronic unpredictable mild stress. Neurosci Bull 26: 297-303, 2010.

28. Ayensu WK, Pucilowski O, Mason GA, Overstreet DH, Rezvani AH and Janowsky DS: Effects of chronic mild stress on serum complement activity, saccharin preference, and corticosterone levels in Flinders lines of rats. Physiol Behav 57: 165-169, 1995.

29. Ostrander MM, Ulrich-Lai YM, Choi DC, Richtand NM and Herman JP: Hypoactivity of the hypothalamo-pituitary-adrenocortical axis during recovery from chronic variable stress. Endocrinology 147: 2008-2017, 2006.

30. Elias AN, Wilson AF, Pandian MR, et al: Corticotropin releasing hormone and gonadotropin secretion in physically active males after acute exercise. Eur J Appl Physiol Occup Physiol 62: 171-174, 1991.

31. Dai X, Thavundayil J and Gianoulakis C: Response of the hypothalamic-pituitary-adrenal axis to stress in the absence and presence of ethanol in subjects at high and low risk of alcoholism. Neuropsychopharmacology 27: 442-452, 2002.

32. Lucassen EA and Cizza G: The hypothalamic-pituitary-adrenal axis, obesity, and chronic stress exposure: Sleep and the HPA axis in obesity. Curr Obes Rep 1: 208-215, 2012.

33. Jones $T$ and Moller MD: Implications of hypothalamic-pituitary-adrenal axis functioning in posttraumatic stress disorder. J Am Psychiatr Nurses Assoc 17: 393-403, 2011.

34. Galina ZH, Sutherland CJ and Amit Z: Effects of heat-stress on behavior and the pituitary adrenal axis in rats. Pharmacol Biochem Behav 19: 251-256, 1983.

35. Megahed GA, Anwar MM, Wasfy SI and Hammadeh ME: Influence of heat stress on the cortisol and oxidant-antioxidants balance during oestrous phase in buffalo-cows (Bubalus bubalis): thermo-protective role of antioxidant treatment. Reprod Domest Anim 43: 672-677, 2008.

36. Sørensen JG, Kristensen TN and Loeschcke V: The evolutionary and ecological role of heat shock proteins. Ecol Lett 6: 1025-1037, 2003.

37. Gupta SC, Sharma A, Mishra M, Mishra RK and Chowdhuri DK: Heat shock proteins in toxicology: how close and how far? Life Sci 86: 377-384, 2010

38. Georgopoulos C and Welch WJ: Role of the major heat shock proteins as molecular chaperones. Annu Rev Cell Biol 9: 601-634, 1993

39. Piano A, Valbonesi $\mathrm{P}$ and Fabbri E: Expression of cytoprotective proteins, heat shock protein 70 and metallothionins, in tissues of Ostrea edulis exposed to heat and heavy metals. Cell Stress Chaperones 9: 134-142, 2004

40. Rhee JS, Raisuddin S, Lee KW, et al: Heat shock protein (Hsp) gene responses of the intertidal copepod Tigriopus japonicus to environmental toxicants. Comp Biochem Physiol C Toxicol Pharmacol 149: 104-112, 2009.

41. Horowitz M: From molecular and cellular to integrative heat defense during exposure to chronic heat. Comp Biochem Physiol A Mol Integr Physiol 131: 475-483, 2002.

42. Yu J and Bao E: Effect of acute heat stress on heat shock protein 70 and its corresponding mRNA expression in the heart, liver, and kidney of broilers. Asian-Aust J Anim Sci 21: 1116-1126, 2008 . 
43. Hiremagalur B, Kvetnansky R, Nankova B, et al: Stress elicits trans-synaptic activation of adrenal neuropeptide $\mathrm{Y}$ gene expression. Brain Res Mol Brain Res 27: 138-144, 1994.

44. McMorris T, Swain J, Smith M, et al: Heat stress, plasma concentrations of adrenaline, noradrenaline, 5-hydroxytryptamine and cortisol, mood state and cognitive performance. Int J Psychophysiol 61: 204-215, 2006.

45. Tai TC, Claycomb R, Siddall BJ, Bell RA, Kvetnansky R and Wong DL: Stress-induced changes in epinephrine expression in the adrenal medulla in vivo. J Neurochem 101: 1108-1118, 2007.

46. Melin B, Curé M, Jimenez C, Koulmann N, Savourey G and Bittel J: Effect of ingestion pattern on rehydrating and exercise performance subsequent to passive dehydration. Eur J Appl Physiol Occup Physiol 68: 281-284, 1994.
47. Tatemoto K, Carlquist M and Mutt V: Neuropeptide Y - a novel brain peptide with structural similarities to peptide YY and pancreatic polypeptide. Nature 296: 659-660, 1982.

48. Kaijser L, Pernow J, Berglund B and Lundberg JM: Neuropeptide $\mathrm{Y}$ is released together with noradrenaline from the human heart during exercise and hypoxia. Clin Physiol 10: 179-188, 1990.

49. Fuller RW: Stress. Neurochemical and humoral mechanisms. Neurochem Int 18: 143, 1991. 